\title{
Restoration principles and criteria: U.S. EPA superfund program policy for cleanup at radiation contaminated sites
}

\author{
S. Walker \\ U.S. Environmental Protection Agency, 1200 Pennsylvania Avenue, NW (5204 P), \\ Washington, DC 20460, USA \\ Science and Policy Branch, Office of Superfund Remediation and Technology Innovation
}

\begin{abstract}
The United States Environmental Protection Agency (EPA) Office of Superfund Remediation and Technology Innovation (OSRTI) is responsible for implementing the long-term (non-emergency) portion of a key U.S. law regulating cleanup: the Comprehensive Environmental Response, Compensation and Liability Act, CERCLA, nicknamed "Superfund." The purpose of the Superfund program is to protect human health and the environment over the long term from releases or potential releases of hazardous substances from abandoned or uncontrolled hazardous waste sites. This paper provides a brief overview of the approach used by EPA to conduct Superfund cleanups at contaminated sites, including those that are contaminated with radionuclides, to ensure protection of human health and the environment. The paper addresses how EPA Superfund determines if a site poses a risk to human health and the framework used to determine cleanup levels. The theme emphasized throughout the paper is that within the Superfund remediation framework, radioactive contamination is dealt with in a consistent manner as with chemical contamination, except to account for the technical differences between radionuclides and chemicals. This consistency is important since at every radioactively contaminated site being addressed under Superfund's primary program for long-term cleanup, the National Priorities List (NPL), chemical contamination is also present.
\end{abstract}

\section{INTRODUCTION}

The United States Environmental Protection Agency (EPA) Office of Superfund Remediation and Technology Innovation (OSRTI) is responsible for implementing the long-term (non-emergency) portion of a key U.S. law regulating cleanup: the Comprehensive Environmental Response, Compensation and Liability Act, CERCLA, commonly known as "Superfund." The purpose of the Superfund program is to protect human health and the environment over the long term from releases or potential releases of hazardous substances from abandoned or uncontrolled hazardous waste sites. The focus of this paper is on Superfund, including how radiation is addressed by the Superfund program.

This paper provides a brief overview of the approach used by EPA to conduct Superfund cleanups at contaminated sites, including those that are contaminated with radionuclides, to ensure protection of human health and the environment. The paper addresses how EPA Superfund determines if a site poses a risk to human health and the framework used to determine cleanup levels. The theme emphasized throughout the paper is that within the Superfund remediation framework, radioactive contamination is dealt with in a consistent manner as with chemical contamination, except to account for the technical differences between radionuclides and chemicals. This consistency is important since at every radioactively contaminated site being addressed under Superfund's primary program for longterm cleanup, the National Priorities List (NPL), chemical contamination is also present.

While every Superfund site is unique, and thus cleanups must be tailored to the specific needs of each site, there are two requirements that must be met at every site. CERCLA requires that all remedial actions at Superfund sites must be protective of human health and the environment. Therefore, cleanup actions are developed with a strong preference for remedies that are highly reliable, provide long-term 
protection and provide treatment of the principle threat to permanently and significantly reduce the volume, toxicity, or mobility of the contamination. In addition, EPA believes that site cleanups should protect ground waters that are current or potential sources of drinking water to drinking water standards whenever practicable. In addition, CERCLA specifically requires Superfund actions to attain or waive the standards and requirements found in other State and Federal environmental laws and regulations. This mandate is known as compliance with "applicable or relevant and appropriate requirements" or ARARs.

\section{REMEDY SELECTION}

A comprehensive regulation known as the National Oil and Hazardous Substances Pollution Contingency Plan or NCP contains the guidelines and procedures for implementing the Superfund program. The NCP reiterates CERCLA's goal of selecting remedies that protect human health and the environment, that maintain protection over time, and that minimize untreated waste. The NCP sets forth nine criteria for selecting Superfund remedial actions. These evaluation criteria are the standards by which all remedial alternatives are assessed and are the basis of the remedy selection process. The criteria can be separated into three levels: threshold, balancing, and modifying. The first two criteria are known as "threshold" criteria. They are a reiteration of the CERCLA mandate that remedies must (1) at a minimum assure protection of human health and the environment and (2) comply with (or waive) requirements of other Federal environmental laws, more stringent State environmental laws and State facility-siting laws. They are the minimum requirements that each alternative must meet in order to be eligible for selection as a remedy.

After the threshold criteria are applied, EPA considers a number of other evaluation criteria. Five of the criteria are known as the "balancing" criteria. These criteria are factors with which tradeoffs between alternatives are assessed so that the best option will be chosen, given site-specific data and conditions. The criteria balance long-term effectiveness and permanence; reduction of toxicity, mobility, or volume; short-term effectiveness; implementability; and cost. The final two criteria are called "modifying" criteria: new information or comments from the State or the community may modify the preferred remedial action alternative or cause another alternative to be considered.

EPA believes the "modifying" criteria concerning new information or comments from the local community is important. In many instances, communities are able to provide valuable information on local history, citizen involvement, and site conditions. To ensure community participation, EPA specifically requires the party conducting the cleanup to conduct a number of activities. For example, EPA conducts community interviews and develops a community relations plan to help EPA determine the community's level of interest in the site, major concerns and issues. EPA creates an information repository and administrative record for every site and makes it available to community members. EPA also develops a document specifically for the community which explains the various clean up options being considered, holds at least one meeting to explain the options and invites the community to submit comments on them. EPA also make funding available to eligible community members so they may obtain technical assistance to better understand the often complex issues associated with cleaning up a Superfund site. By identifying the public's concerns, EPA is able to fashion a response that more effectively addresses the community's need.

\subsection{Risk assessment}

To help meet the Superfund program's mandate to protect human health and the environment from current and potential threats posed by uncontrolled hazardous substance releases (both radiological and nonradiological), EPA has developed a human health evaluation process as part of its remedial response program. The process of gathering and assessing human health risk information is adapted from well-established chemical risk assessment principles and procedures. The Superfund Baseline Risk 
Assessment provides the EPA's estimate of the likelihood and magnitude of health problems occurring if no cleanup action is taken at a site.

\subsection{Risk-based cleanup levels}

Cleanup levels for radioactive contamination at CERCLA sites are generally expressed in terms of risk levels, rather than millirem or millisierverts, as a unit of measure. CERCLA guidance recommends the use of slope factors in the EPA Health Effects Assessment Summary Tables (HEAST) when estimating cancer risk from radioactive contaminants, rather than converting from millirem. HEAST is based on risk coefficients in Federal Guidance Report 13.

Compliance with the requirements of other Federal environmental laws, more stringent State environmental laws, or State facility-siting laws is often the determining factor in establishing cleanup levels at CERCLA sites. These requirements are known as Applicable or Relevant and Appropriate Requirements (ARARs). However, where ARARs are not available or are not sufficiently protective, EPA generally sets site-specific remediation levels for: 1) carcinogens at a level that represents an upperbound lifetime cancer risk to an individual of between $10^{-4}$ to $10^{-6}$; and for 2) non-carcinogens such that the cumulative risks from exposure will not result in adverse effects to human populations (including sensitive sub-populations) that may be exposed during a lifetime or part of a lifetime, incorporating an adequate margin of safety. The specified cleanup levels account for exposures from all potential pathways, and through all media (e.g., soil, ground water, surface water, sediment, air, structures, and biota).

The $10^{-4}$ to $10^{-6}$ cancer risk range can be interpreted to mean that a highly exposed individual may have a one in 10,000 to one in 1,000,000 increased chance of developing cancer because of exposure to a site-related carcinogen. Once a decision has been made to take an action, EPA prefers cleanups achieving the more protective end of the range (i.e., $10^{-6}$ ). EPA uses $10^{-6}$ as a point of departure and establishes Preliminary Remediation Goals (PRGs) at $1 \times 10^{-6}$.

To assess the potential for cumulative noncarcinogenic effects posed by multiple contaminants, EPA has developed a hazard index (HI). The HI is derived by adding the noncancer risks for site contaminants with the same target organ or mechanism of toxicity. When the HI exceeds 1.0, there may be concern for adverse health effects due to exposure to multiple contaminants. Radioisotopes of uranium are generally the only radionuclides for which EPA will evaluate the HI.

\subsubsection{Combining radionuclide and chemical risk}

Excess cancer risk from both radionuclides and chemical carcinogens should be summed to provide an estimate of the combined risk presented by all carcinogens. Exceptions would be cases in which a person cannot reasonably be exposed to both chemical and radiological carcinogens. Similarly, the chemical toxicity from uranium should be combined with that of other site-related contaminants in calculating the HI.

There are generally several differences between cancer slope factors (the cancer risk (i.e., proportion affected) per unit of dose used in EPA's Integrated Risk Information System chemical files) for radionuclides and chemicals. However, similar differences also occur between different chemical slope factors. In the absence of additional information, it is reasonable to assume that excess cancer risks are additive for purposes of evaluating the total incremental cancer risk associated with a contaminated site.

\subsubsection{PRGS}

PRGs are used for site "screening" and as initial cleanup goals if applicable. PRGs are not de facto cleanup standards and should not be applied as such. The PRG's role in site "screening" is 
to help identify areas, contaminants, and conditions that do not require further federal attention at a particular site.

PRGs not based on ARARs are risk-based concentrations, derived from standardized equations combining exposure information assumptions with EPA toxicity data. PRGs based on cancer risk are established at $1 \times 10^{-6}$. PRGs are identified early in the CERCLA process. PRGs are modified as needed based on site-specific information.

\subsubsection{Superfund risk and dose soil and water models}

EPA has developed a PRG for Radionuclides electronic calculator, known as the Rad PRG calculator. This electronic calculator presents risk-based standardized exposure parameters and equations that should be used for calculating radionuclide PRGs for residential, commercial/industrial, and agricultural land use exposures, tap water and fish ingestion exposures. The calculator also presents PRGs to protect groundwater which are determined by calculating the concentration of radioactively contaminated soil leaching from soil to groundwater that will meet MCLs or risk-based concentrations. The Rad PRG calculator may be found at: http://epa-prgs.ornl.gov/radionuclides/.

To address ARARs that are expressed in terms of millirem per year, an approach similar to that taken for calculation of PRGs was also used to calculate soil "compliance concentrations" based upon various methods of dose calculation in another EPA tool, the "Dose Compliance Concentrations", or DCC calculator. The DCC calculator equations are identical to those in the PRG for Radionuclides, except that the target dose rate (ARAR based) is substituted for the target cancer risk $\left(1 \times 10^{-6}\right)$, the period of exposure is one year to indicate year of peak dose, and a DCF will be used in place of the slope factor. The DCC calculator may be found at: http://epa-dccs.ornl.gov/.

\subsubsection{Superfund decommissioning models}

EPA has recently completed one risk assessment tool, and is close to completion of another that are particularly relevant to decommissioning activities conducted under CERCLA authority. EPA developed the Preliminary Remediation Goals for Radionuclides in Buildings (BPRG) electronic calculator to help standardize the evaluation and cleanup of radiologically contaminated buildings at which risk is being assessed for occupancy. BPRGs are radionuclide concentrations in dust, air and building materials that correspond to a specified level of human cancer risk. The BPRG calculator may be found at: http://epabprg.ornl.gov/.

The intent of the draft Preliminary Remediation Goals for Radionuclides in Outside Surface SPRG calculator is to address hard outside surfaces such as building slabs, outside building walls, sidewalks and roads. SPRGs are radionuclide concentrations in dust and hard outside surface materials. The BPRG and SPRG calculators include both residential and industrial/commercial exposure scenarios.

To facilitate compliance with dose-based ARARs while conducting decommissioning activities under CERCLA, EPA is developing two electronic calculators. These are the Radionuclide Building Dose Cleanup Concentrations (BDCC) and the Radionuclide Outside Hard Surfaces Dose Cleanup Concentrations (SDCC) electronic calculators. Both of these ARAR dose calculators are set up in a similar manner to the BPRG and SPRG calculators. They include the same exposure scenarios. Also, the equations in the scenarios are essentially the same except the ARAR dose calculators use: dose conversion factors instead of slope factors, and a year of peak dose instead of risk over a period of exposure such as 30 years.

\subsubsection{Superfund ecological risk model}

EPA is also developing the "Radionuclide Ecological Benchmark" calculator. This calculator provides biota concentration guides (BCGs), also known as ecological screening benchmarks, for use in 
ecological risk assessments at CERCLA sites. This calculator is intended to develop ecological benchmarks as part of the EPA guidance "Ecological Risk Assessment Guidance for Superfund: Process for Designing and Conducting Ecological Risk Assessments." The calculator develops ecological benchmarks for ionizing radiation based on cell death only.

\section{COMPLIANCE WITH ENVIRONMENTAL LAWS}

Compliance with (or waiver of) requirements of other Federal environmental laws, more stringent State environmental laws and State facility-siting laws is a cornerstone of CERCLA. Cleanups conducted under the Superfund program must comply with these laws unless a waiver is justified. These laws, as well as ARARs, assist EPA in identifying preliminary remediation goals and alternatives. Complying with ARARs both during the implementation and upon completion of an action helps the lead agency define the ways in which the activity can be carried out in a manner that is protective of human health and the environment.

Because the diverse characteristics of Superfund sites preclude the development of prescribed ARARs, it is necessary to identify ARARs on a site-by-site basis. There are many radiation standards that are likely to be used as ARARs to establish cleanup levels or to conduct remedial actions. Some of the radiation standards most frequently used as ARARs at Superfund sites are the soil cleanup and indoor radon standards developed to address contamination at sites that are subject to the Uranium Mill Tailings Radiation Control Act of 1978 (UMTRCA). When used as an ARAR at Superfund sites, the soil cleanup level for radium 226 and radium 228 combined, or thorium 230 and thorium 232 combined, is 5 picoCuries per gram $(\mathrm{pCi} / \mathrm{g})$ [0.185 Becquerel per gram $(\mathrm{Bq} / \mathrm{g})]$ above background, while the indoor radon level is 0.02 working levels inclusive of background. For a list of "Likely Federal Radiation Applicable or Relevant and Appropriate (ARARs)", see Attachment A of EPA's guidance "Establishment of Cleanup Levels for CERCLA sites with Radioactive Contamination" at: http://www.epa.gov/superfund/health/contaminants/radiation/pdfs/radguide.pdf.

\section{GROUNDWATER}

One extremely important ARAR that should be noted are Maximum Contaminant Levels (MCLs) that are established under the United States law for drinking water standards, called the Safe Drinking Water Act. EPA believes contaminated ground water should be restored to beneficial use, whenever practicable. This means that sites where the contaminated ground water is a potential or current source of drinking water should be remediated to concentrations corresponding to drinking water standards (e.g., concentrations corresponding to MCLs or more stringent State drinking water standards). The Superfund program requires MCLs be met within the aquifer, not at the tap. EPA's phased approach to addressing contaminated groundwater at CERCLA sites is discussed in "Presumptive Response Strategy and Ex-Situ Treatment Technologies for Contaminated Ground Water at CERCLA Sites, Final Guidance, which may be found at: http://www.epa.gov/superfund/health/conmedia/gwdocs/gwguide/index.htm.

EPA's policy is to defer to State determinations of ground-water use when such determinations are based on a Comprehensive State Ground Water Protection Program (CSGWPP) that has 1) been endorsed by EPA and 2) allows such determinations to be made at specific sites. In the absence of a CSGWPP, EPA considers other state classification schemes and EPA's classification guidelines which use criteria defining ground waters of sufficient quantity and quality to supply the needs of a single family household. EPA's use of CSGWPP's at CERCLA sites is discussed in "The Role of CSGWPPs in EPA Remediation Programs" which may be found at: http://www.epa.gov/superfund/health/conmedia/gwdocs/pdfs/role.pdf.

The current MCLs for radionuclides are set at $4 \mathrm{mrem} / \mathrm{yr}$ [0.04 millisieverts per year (mSv/yr)] to the whole body or an organ for the sum of the doses from beta particles and photon emitters, 15 picoCuries per liter (pCi/l) [0.555 Becquerels per liter $(\mathrm{Bq} / \mathrm{l})]$ for gross alpha, and $5 \mathrm{pCi} / 1$ 
[0.185 Bq/l] combined for radium-228 and radium-226, and 30 micrograms per liter of uranium. EPA has published concentration tables for each radionuclide that correspond to the $4 \mathrm{mrem} / \mathrm{yr}$ MCL which may be found at: http://www.epa.gov/safewater/radionuclides/pdfs/guide_radionuclides_tablebetaphotonemitters.pdf.

\section{OTHER CRITERIA, ADVISORIES, AND GUIDANCE}

Many Federal and State environmental and public health agencies develop criteria, advisories, guidance, and proposed standards that are not legally enforceable but contain information that would be helpful in carrying out selected remedies, or in determining their protectiveness. These materials are meant to complement the use of ARARs, not to compete with or replace them. Because they are not ARARs, their identification and use are not mandatory. These are known as to-be-considered (TBC) material. However, it is EPA's policy that dose-based (millirem or millisievert) recommendations should generally not be used as TBCs. Sometimes the Superfund program develops guidance on interpreting a particular ARAR to assist site decision makers. These guidance documents on compliance with ARARs at radioactively contaminated CERCLA sites may be found at the following webpage: http://www.epa.gov/superfund/health/contaminants/radiation/radarars.htm.

\section{LAND USE/INSTITUTIONAL CONTROLS}

The concentration levels for various media that correspond to the acceptable risk level established for cleanup will depend in part on land use at the site. Land uses that will be available following completion of a response action are determined as part of the remedy selection process considering the reasonably anticipated land use or uses along with other remedy selection factors. EPA's policies for how to determine a sites reasonably anticipated land use is discussed in "Land Use in the CERCLA Remedy Selection Process", which may be found at: http://www.epa.gov/superfund/community/relocation/ landuse.pdf.

Institutional controls are generally included as a supplemental component to cleanup alternatives, not as a substitute for treatment or containment. Institutional controls are non-engineering measures usually, but not always legal controls - intended to affect human activities in a way that prevents or reduces exposure to hazardous substances. Institutional controls usually restrict land use to prevent unanticipated changes in use that could result in unacceptable exposures to residual contamination. At a minimum, institutional controls are intended to alert future users to the residual risks and the need to monitor for any changes in use. EPA's CERCLA policy states that if a site cannot be cleaned up to a protective level (i.e., generally within the $10^{-4}$ to $10^{-6}$ risk range) for the "reasonably anticipated future land use" because it is not cost-effective or practicable, then a more restricted land use should be chosen that will meet a protective level.

Where waste is left on-site at levels that would require limited use and restricted exposure to ensure protectiveness, EPA will conduct reviews at least once every five years to monitor the site for any changes including changes in land use. Such reviews need to analyze the implementation and effectiveness of any institutional controls with the same degree of care as other parts of the remedy. Should land use change in spite of land use restrictions, it will be necessary to evaluate the implications of that change for the selected remedy, and whether the remedy remains protective.

\section{COMMUNITY INVOLVEMENT TOOLS}

EPA has developed two tools to facilitate public involvement at radioactively contaminated Superfund sites which may be found at the following webpage: http://www.epa.gov/superfund/health/ contaminants/radiation/radcomm.htm. 
The first is a booklet entitled "Common Radionuclides Found at Superfund Sites." The information in this booklet is intended to help the general public understand more about the various common radionuclides found at Superfund sites. The booklet contains 12 radionuclide-specific fact sheets that answer questions such as: How can a person be exposed to the radionuclide?, How can it affect human health?, How does it enter and leave the body?, What levels of exposure result in harmful effects?, and What recommendations has EPA made to protect human health from the radionuclide?

The second is a video entitled "Superfund Radiation Risk Assessment and How you can Help, an Overview." This 19 minute video describes the Superfund risk assessment process for radioactive contamination: what it is, how it works, and most importantly, how members of the public can be involved.

\section{CLOSING}

Actions under Superfund must result in the protective cleanup of sites. The CERCLA framework for addressing hazardous sites ensures that risks from radiological contamination will be addressed in a manner consistent with risks from non-radiological contamination, except to account for technical differences posed by radionuclides, and that cleanups for all contaminants will achieve protection of human health and the environment. The same set of principles and decision making criteria apply equally to both chemical and radioactive hazards. The goal is to provide lasting, protective site restoration while taking into account the cost and achievability of different approaches to attaining these protective goals.

For more information and copies of EPA guidance documents for addressing radioactively contaminated CERCLA sites, see the EPA's Superfund Radiation webpage at: http://www.epa.gov/ superfund/health/contaminants/radiation/index.htm.

For more information and copies of EPA guidance documents for developing cleanup levels for long-term CERCLA sites, see EPA's Remedy Decisions webpage at http://www.epa.gov/superfund/ policy/remedy/sfremedy/index.htm.

Both of these webpages contain numerous OSWER Directives, which are EPA's official guidance for the Superfund program, and other material that is useful for cleaning up CERCLA sites. 
